\title{
Promising assets of Southern Africa? \\ Cyclopia genistoides and Hoodia gordonii
}

\author{
Summary of Ph.D. Thesis
}

Orsolya Roza

Department of Pharmacognosy

University of Szeged

Szeged

2016 
University of Szeged

Graduate School of Pharmaceutical Sciences

Programme of Pharmacognosy

Head: Prof. Judit Hohmann DSc.

Department of Pharmacognosy

Supervisors: Prof. Judit Hohmann DSc., Dezső Csupor PhD.

Orsolya Roza

\section{Promising assets of Southern Africa? \\ Cyclopia genistoides and Hoodia gordonii}

Summary of Ph.D. Thesis

Final Exam Committee:

Head: Prof. Imre Máthé DSc.

Members: Ágnes Kéry PhD., Zoltán Kele PhD.

Reviewer Committee:

Head: Prof. Gyöngyvér Soós PhD.

Reviewers: Gábor Janicsák PhD., Tamás Kőszegi PhD.

Member: Péter Molnár DSc.

Szeged, Hungary 


\section{INTRODUCTION}

Menopause and obesity are amongst the most prevalent health problems. By 2030 it is projected that approximately 47 million women will go through menopause every year worldwide. Obesity has become an epidemic, $65 \%$ of the world's population lives in countries where overweight and obesity kills more people than underweight. Tackling chronic diseases is high priority, taken into consideration the size of the affected population. Obesity and menopause are lacking safe and effective treatment; hence new approaches are urgently needed. The aim of my work was to investigate secondary metabolites from Southern African plants, which may be used in the treatment of the upper mentioned conditions.

The Southern African flora is remarkably distinct. The Cape Floristic Region covers less than $4 \%$ of Southern Africa, yet includes almost half of its species, 8550 , of which $73 \%$ are endemic. Evidently the Southern African traditional medicine is rich, using circa 3000 medicinal plants. Cyclopia genistoides and Hoodia gordonii are amongst those few, about 40, Southern African indigenous species, which have been commercialised to some extent. Their therapeutic potential is notable based on previous pharmacological studies and their traditional use; however they have poorly examined pharmacology and chemistry.

The tea prepared from the fermented herbs of Cyclopia species (Fabaceae) is traditionally used as restorative or expectorant, but anecdotal evidence also exists about their consumption in order to stimulate milk production in breast-feeding women and to alleviate menopausal symptoms. Four species (C. intermedia E. Mey., C. genistoides (L.) Vent., C. sessiliflora Eckl. \& Zeyh. and C. subternata Vogel) are marketed and consumed worldwide as honeybush tea; named due to their natural sweetness and honey-like aroma.

Cyclopia species contain a wide range of phenolic constituents, such as xanthones, flavonoids and isoflavones. The high polyphenolic content is likely to responsible for the studied oestrogenlike effect. Methanol extracts from $C$. genistoides was reported to consistently have the highest binding affinity for both oestrogen receptor (ER) subtypes in whole-cell competitive receptor binding assays, when comparing four Cyclopia species.

Hoodia gordonii (Apocynaceae) is consumed by Bushmen in Southern Africa in order to reduce appetite. Its proposed active compound for weight-loss is P57, an oxypregnane glycoside, but the mechanism of action of Hoodia is still unknown. Next to the controversial appetitesuppressant effects, demonstrated in some in vivo experiments, there was only one human clinical study performed, which reported significant increase in blood pressure and pulse rate. Taking into 
consideration that these alarming side effects are typical for some effective weight loss drugs, and that the composition of Hoodia spp. has not yet been fully mapped, it is possible that a group of compounds other than pregnane glycosides may be responsible for the reported side effects or for the appetite suppressant activity of $H$. gordonii.

\section{AIMS OF THE STUDY}

The aim of the present work was to explore the potential of metabolites of two Southern African medicinal plants in the treatment of obesity and menopause.

In order to achieve these aims, the main tasks were to:

- $\quad$ investigate the mechanism of action of Hoodia gordonii that is possibly also in the background of reported side effects

- develop analytical method for the authentication of Hoodia-based products

- perform bioactivity guided fractionation of $C$. genistoides in order to identify secondary metabolites with phytoestrogenic activity

- $\quad$ isolate compounds from C. genistoides by a combination of various chromatographic methods (CC, VLC, RPC, MPLC, PLC and HPLC)

- $\quad$ elucidate the structures of the isolated compounds by NMR and MS methods, provide missing NMR data on the already-known constituents

- compare the content of active compounds, isolated from fermented and nonfermented honeybush teas

- examine the effect of probiotic bacteria on flavonoid glycosides isolated from C. genistoides, in order to investigate the possible role of intestinal bacterial flora in the metabolism of flavonoid glycosides and the bioavailability of aglycones of honeybush tea

- $\quad$ determine the antiproliferative effects of phytoestrogens isolated from C. genistoides

- evaluate the xanthine oxidase inhibitory activity of the isolated compounds of C. genistoides. 


\section{MATERIALS AND METHODS}

For the comparison of a Hoodia product (Hoodia spray) with authentic plant material, the extract of $\mathrm{H}$.gordonii was prepared for high-performance liquid chromatography (HPLC) and high performance thin-layer chromatography (HPTLC) analyses from fresh ground plant material with $\mathrm{AcNi}$, using ultrasonic bath. The Hoodia spray was used directly for these studies. For the investigation of falsification of this product, the Hoodia spray itself was used for thin-layer chromatography (TLC) and mass-spectroscopy (MS) analyses. The Hoodia spray was evaporated to dryness, and then the residue was dissolved with physiological saline-DMSO (95:5), and after filtered to perform the organ baths studies.

The dried fermented and non-fermented herbs of $C$. genistoides were extracted via ultrasonication with methanol. The extract was concentrated in vacuo, then diluted with $\mathrm{H}_{2} \mathrm{O}$, and liquid-liquid partition was performed, affording $n$-hexane, dichloromethane, ethyl-acetate, the remnant aqueous layers and insoluble part.

The compounds were isolated by multistep chromatographic methods, including column chromatography $(\mathrm{CC})$, vacuum-liquid chromatography $(\mathrm{VLC})$, rotation planar chromatography (RPC), medium-pressure liquid chromatography (MPLC), preparative layer chromatography (PLC), gel filtration (OCC-SPh) and HPLC. Normal- or reversed-phase $\mathrm{SiO}_{2}$ (NP/RP), polyamide or Sephadex LH-20 were applied as stationary phases.

The isolated compounds were characterized and their structures were elucidated by means of different spectroscopic methods (NMR, HRESIMS, ESIMS, APCIMS and UV).

For HPLC quantitative determination of compounds, the dried fermented and non-fermented plant materials of $C$. genistoides were extracted with boiling tap water ("cup of tea"). For comparison a methanolic extract was also prepared.

In the course of the bacterial fermentation study, aqueous extracts of the fermented and non-fermented $C$. genistoides were prepared. After lyophilisation, the dry residues were dissolved in DMSO and physiologic saline solution and mixture of probiotic bacteria was added to each solution. These mixtures were mixed at $37{ }^{\circ} \mathrm{C}$ for 50 hours, and then objected to HPLC analyses.

The phytoestrogenic effects of the $\mathrm{CH}_{2} \mathrm{Cl}_{2}$ and the EtOAc extracts from the fermented and non-fermented $C$. genistoides and the isolated compounds thereof were assessed in vitro in the transgenic $p E R 8$ :GUS system.

The compounds of $C$. genistoides were tested for antiproliferative activity in vitro against human tumour cell lines (A2780 (ovarian carcinoma), and T47D (breast carcinoma).

The xanthine-oxidase inhibitor activity of the isolated compounds was also analysed. 


\section{RESULTS AND DISCUSSION}

\section{Sympathomimetic activity of Hoodia product}

The only available human clinical study on Hoodia gordonii reported no change in body weight or energy expenditure; however, administration of a purified $H$. gordonii extract was associated with significant increase in blood pressure and pulse rate. Similar side effects have been reported to the Department of Pharmacognosy, University of Szeged, by consumers of a product available on the Hungarian market (Hoodia spray). Hence, as a first step, the comparison of the product with authentic plant material was performed alongside with testing for possible adulterants with potential for causing cardiovascular side effects (e.g. sibutramine, amphetamine derivatives). Then the effect of the Hoodia spray on $\beta$-adrenergic receptors in rat uterus was measured to explore the potential role of $\beta$-adrenergic receptor agonist activity in the possible cardiovascular adverse effects of the plant.

\section{Comparison of the Hoodia product with authentic plant material}

\section{and investigation of its falsification}

First, P57, a characteristic compound of Hoodia, was chosen for mass spectrometric identification using multiple reaction monitoring (MRM) mode. Both $\mathrm{m} / \mathrm{z} 311.3$ and $\mathrm{m} / \mathrm{z} 785.5$ product ions were detected with the precursor ion $\mathrm{m} / \mathrm{z} 885.5$, indicating that P57 is present in the Hoodia spray. The aglycone was identified too, with the product ions of $\mathrm{m} / \mathrm{z} 319.3$ and $\mathrm{m} / \mathrm{z} 337.3$. All of these transitions have been reported in the literature for P57.

The similarities of chromatograms of the plant extract and the product confirmed that the commercial product was based on Hoodia extract. Sibutramine, amphetamine, methamphetamine and ephedrine, were not detected in the product.

\section{Beta-adrenergic receptor agonist activity}

$\beta$-adrenergic receptor agonists are reported to decrease food intake and exhibit anorectic properties. Stimulation of $\beta$-adrenoceptors also results in different cardiovascular symptoms. Since cardiovascular side effects have been reported for a $H$. gordonii extract, the stimulation of $\beta$-adrenergic receptors seemed to be a rational explanation for the mechanism of its anorectic action. Both $\alpha$ - and $\beta$-adrenergic receptors play crucial roles in the motor activity of myometrial smooth muscle, eliciting contraction and relaxation, respectively. In a set of in vitro organ bath experiments, the myometrial effects of the $H$.gordonii extract-containing product were monitored against spontaneous and $\mathrm{KCl}$-stimulated contractions of uterine rings from nonpregnant and late-pregnant (day 22) rats. All experiments were performed with and without 
nonselective $\beta$-antagonist propranolol $(10 \mu \mathrm{M})$. The product elicited a marked and concentrationdependent relaxation against both spontaneous and stimulated contractions. The inhibition of spontaneous contractility was significantly decreased in the presence of propranolol. The relaxing effect of the spray was substantially less pronounced on uteri from late-pregnant animals, but propranolol significantly modified it.

The gestation-dependent myometrial effect (weaker relaxing effect on uteri from latepregnant animals) of substances acting on the sympathetic system could be explained by the changes in the receptor function during pregnancy. The nonpregnant uterus of the rat exhibits limited $\alpha$-adrenoceptor-mediated contraction but efficiently relaxed by $\beta$-adrenergic stimulation. Late-pregnant myometrium is sensitive to both $\alpha$ - and $\beta$-adrenergic stimulation, and therefore, the overall response is determined by the receptor preference of the tested substance. It is plausible that the limited relaxation of late-pregnant myometrium, induced by the product, is a consequence of a balanced $\alpha$ - and $\beta$-adrenoceptor stimulation that can be shifted towards increased contractility by masking the action, mediated through $\beta$-receptors.

Based on the propranolol-sensitive component of the uterine action of the product, a sympathomimetic effect with substantial $\beta$-receptor-mediated contribution is proposed. The results support the cardiovascular side effects reported in a human clinical trial (increase in blood pressure, pulse, heart rate). Since the tested Hoodia commercial product possesses sympathomimetic effects, its use can cause both appetite suppression and increased thermogenesis, resulting in weight loss.

The recorded sympathomimetic effect with substantial $\beta$-receptor-mediated contribution is similar to the mechanism of action of several already withdrawn weight loss medications. Thus, if a Hoodia product consumption results in weight-loss, the reported side effects most likely will manifest.

\section{Isolation of compounds}

The purification of the $\mathrm{CH}_{2} \mathrm{Cl}_{2}$-soluble phases of the fermented and non-fermented $C$. genistoides were performed by CC on polyamide and afforded 14 and 12 main fractions (P1-P14 and PP1PP12). The EtOAc layer from the non-fermented C. genistoides was subjected to VLC on silica gel, and twelve combined fractions (V1-V12) were yielded. Several fractions showed either oestrogenic or xanthine oxidase inhibitory or antiproliferative activity or interesting chemical composition (according to TLC monitoring). Since the fractions demonstrated chemical complexity, they were subjected to a multistep chromatographic procedure (MPLC, HPLC, PLC, 
RPC, CC) in order to isolate the compounds (CG1-CG17), with the use of silica gel (RP/NP) or Sephadex LH-20 and different solvent systems (Figure 1).
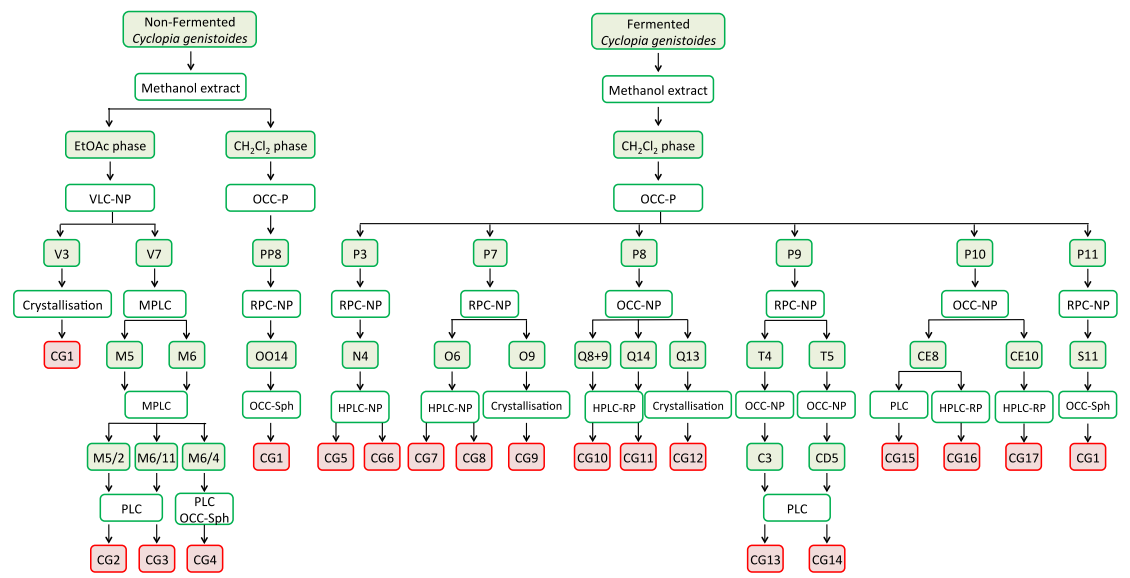

Figure 1. Isolation of compounds from $C$. genistoides

\section{Characterisation and structure elucidation of the isolated compounds}

The structures of the isolated compounds were determined by means of spectroscopic methods. High-resolution mass spectrometric measurements allowed the determination of the exact molecular weight and molecular composition of the compounds. The most useful methods in the structure elucidation were 1D and 2D NMR experiments including ${ }^{1} \mathrm{H}-\mathrm{NMR},{ }^{13} \mathrm{C}-\mathrm{NMR}, \mathrm{JMOD},{ }^{1} \mathrm{H}-{ }^{1} \mathrm{H}$ COSY, HSQC and HMBC experiments, and the relative configurations were then characterized with the aid of NOESY spectra.

CG2 and CG3 were identified as benzophenone derivatives based on their spectral characteristics. CG2 was identified as iriflophenone $2-0-\beta$-glucopyranoside by comparing its spectral data with those reported in the literature. CG3 proved to be identical with iriflophenone 3-C- $\beta$-glucopyranoside, isolated earlier from $C$. genistoides and $C$. subternata.

CG7 and CG8 were found to have a pterocarpan nucleus, substituted with methylenedioxy, hydroxy and methoxy groups. After detailed MS and NMR studies CG8 could be identified as (6aR,11aR)-(-)-maackiain and CG7 as (6aR,11aR)-(-)-2-methoxymaackiain. Two-dimensional NMR investigations, including ${ }^{1} \mathrm{H}-{ }^{1} \mathrm{H}$ COSY, NOESY, $\mathrm{HSQC}$ and $\mathrm{HMBC}$ experiments, permitted unpublished ${ }^{1} \mathrm{H}$ and ${ }^{13} \mathrm{C}$ assignments for both compounds. This is the first isolation of 2methoxymaackiain and maackiain from the Cyclopia genus; previously these compounds were published only from Ulex and other Fabaceae species. 
The further compounds were identified by comparing of their physical and spectroscopic data with reported data as luteolin (CG1), naringenin 5-O- $\beta$-glucoside (= helichrysin B) (CG4), afrormozin (CG9), formononetin (CG10), liquiritigenin (CG11), naringenin (CG13), 5,7,3',5'tetrahydroxyflavanone (CG14), genistein (CG15), isoliquiritigenin (CG16) and diosmetin (CG17). CG5 was identified as piceol (= 4-hydroxyacetophenone) and CG6 as 4-hydroxybenzaldehide based on their ${ }^{1} \mathrm{H}$-, ${ }^{13} \mathrm{C}$-NMR and MS data. The ${ }^{1} \mathrm{H}$ - and ${ }^{13} \mathrm{C}$-NMR data of hesperetin (CG12) were in good agreement with literature data, but in DMSO- $\mathrm{d}_{6}$ are reported for the first time.

Fractionation (mainly bioactivity guided) of Cyclopia genistoides led to the isolation of 17 compounds. Fourteen compounds were first isolated from the species [(iriflophenone 2-O- $\beta$ glucopyranoside (CG2), helichrysin B (CG4), piceol (CG5), 4-hydroxybenzaldehid (CG6), (-)-2methoxymaackiain (CG7), (-)-maackiain (CG8), afrormozin (CG9), formononetin (CG10), liquiritigenin (CG11), naringenin (CG13), 5,7,3', $5^{\prime}$-tetrahydroxyflavanone (CG14), genistein (CG15), isoliquiritigenin (CG16), diosmetin (CG17)] and ten compounds from the genus Cyclopia [iriflophenone 2-O- $\beta$-glucopyranoside (CG2), helichrysin B (CG4), piceol (CG5), 4hydroxybenzaldehid (CG6), (-)-2-methoxymaackiain (CG7), (-)-maackiain (CG8), liquiritigenin (CG11), 5,7,3', 5'-tetrahydroxyflavanone (CG14), genistein (CG15) and isoliquiritigenin (CG16)]. Interestingly naringenin was present in the plant in high quantities, despite the fact that in two studies it was declared absent according to HPLC determination. Genistein - usually used as positive reference in phytoestrogenic studies - was also found in the herbal substance.<smiles>O=c1cc(-c2ccc(O)c(O)c2)oc2cc(O)cc(O)c12</smiles>

CG1<smiles>COc1cc(O)cc(O)c1C(=O)c1ccc(O)cc1</smiles>

CG2<smiles>O=C(c1ccc(O)cc1)c1c(O)cc(O)c(Cl)c1O</smiles>

CG3<smiles>COc1cc(O)cc2c1C(=O)CC(c1ccc(O)cc1)O2</smiles>

CG4<smiles>COc1cc2c(cc1O)OC[C@H]1c3cc4c(cc3O[C@H]21)OCO4</smiles><smiles>Oc1ccc2c(c1)OC[C@@H]1c3cc4c(cc3O[C@H]21)OCO4</smiles>

CG5 CG6

CG7 CG8<smiles>COc1ccc(-c2coc3cc(O)c(OC)cc3c2=O)cc1</smiles>

CG9<smiles>COc1ccc(-c2coc3cc(OC)c(O)cc3c2=O)cc1</smiles>

CG10<smiles>O=C1CC(c2ccc(O)cc2)Oc2cc(O)ccc21</smiles>

CG11 
<smiles>COc1ccc(C2CC(=O)c3c(O)cc(O)cc3O2)cc1O</smiles>

CG12<smiles>O=C1CC(c2ccc(O)cc2)Oc2cc(O)cc(O)c21</smiles>

CG13<smiles>O=C1CC(c2cc(O)cc(O)c2)Oc2cc(O)cc(O)c21</smiles>

CG14<smiles>O=c1c(-c2ccc(O)cc2)coc2cc(O)cc(O)c12</smiles>

CG15<smiles>O=C(/C=C/c1ccc(O)cc1)c1ccc(O)cc1O</smiles>

CG16<smiles>COc1ccc(-c2cc(=O)c3c(O)cc(O)cc3o2)cc1O</smiles>

CG17

\section{Oestrogen-like activity}

The methanol extracts from fermented and non-fermented C. genistoides were assayed with a highly efficient and convenient transgenic plant system, Arabidopsis thaliana pER8:GUS line, in order to detect oestrogenic/anti-oestrogenic activity. The transgenic plant pER8:GUS, has the ability to detect both ER agonists and antagonists and can be used to quantify the bioactivity of phytoestrogens. The system contains an oestrogen receptor-based transactivator vector (XVE) as an activator unit and the GUS ( $\beta$-glucuronidase) gene as a reporter. The XVE activator comprises the regulation region of the ER- $\alpha$, hence only determines ER- $\alpha$ interactions. It is strictly regulated by oestradiol; in case of the presence of oestrogen active compounds the activator stimulates the expression of GUS transcription. It is a visible system, primary results can be readily observed visually, because the GUS protein containing transgenic plants give blue colour, after adding a glucopyranosiduronic acid containing dye.

After the solvent-solvent partition of the methanolic extracts of the fermented and nonfermented herb of Cyclopia genistoides, the $n$-hexane, EtOAc, $\mathrm{CH}_{2} \mathrm{Cl}_{2}$ and aqueous $\mathrm{MeOH}$ layers were screened by the transgenic plant pER8:GUS reporter system at 100 and $200 \mu \mathrm{g} / \mathrm{ml}$. Oestrogenic activity of the extracts was detected via a histochemical assay for GUS activity. The $\mathrm{CH}_{2} \mathrm{Cl}_{2}$ and EtOAc layers of the fermented and non-fermented $C$. genistoides were proved to be active, thus were selected for bioactivity-guided fractionation, by the means of HPLC, MPLC, VLC, RPC, CC and PLC. From the $\mathrm{CH}_{2} \mathrm{Cl}_{2}$ fraction of the fermented plant material four out of fourteen subfractions, yielded via polyamide column chromatography, exhibited oestrogen-like effects (P8$\mathrm{P} 11, \mathrm{MAC} \leq 200 \mu \mathrm{g} / \mathrm{ml}$ ). P9 yielded CG13, CG14, fraction P10 afforded CG15, CG16 and P11 
furnished CG1 (Figure 1). Fractions P8 and P10 were also analysed by HPLC and CG13 and CG14 were also detected from these fractions, respectively. From the EtOAc fraction of the nonfermented $C$. genistoides four out of twelve VLC subfractions were active in the oestrogen-like reporter assay (V2, V3, V6, V7, MAC $\leq 200 \mu \mathrm{g} / \mathrm{ml}$ ). The active constituent CG1 and CG4 were isolated from active fractions V3 and V7, respectively (Figure 1). Active fractions V2 and V3 were also chromatographed by HPLC. CG14 was detected in both fractions, whileCG13 only in V2..

Bioassay-directed chromatographic fractionation led to the isolation of six flavonoids with oestrogenic activity: CG1, CG4, CG13, CG14, CG15, and CG16, luteolin, helichrysin B (naringenin-5O- $\beta$-glucoside), naringenin, 5,7,3',5'-tetrahydroxyflavanone, genistein and isoliquiritigenin, respectively.

The least potent compound was helichrysin B with a minimum active concentration (MAC) of $115 \mu \mathrm{M}$ (Figure 2). Two compounds, which have not yet been isolated from C. genistoides, genistein and isoliquiritigenin exhibited substantial effect with a MAC of $<11.56$ and $12.19 \mu \mathrm{M}$. Luteolin, naringenin and 5,7,3',5'-tetrahydroxyflavanone possessed oestrogen-like activity too, with a MAC of $87.5,23$ and $86.5 \mu \mathrm{M}$. The minimum active concentration of the control, oestradiol $\left(E_{2}\right)$ was found to be $2.5 \mathrm{nM}$.

Luteolin, genistein, isoliquiritigenin and naringenin are widely known phytoestrogens. Genistein (54 mg/day) was found to have positive effects on bone mineral density on osteopenic postmenopausal women. Isoliquiritigenin is also a promising agent for bone destructive diseases. Genistein and luteolin in vitro suppressed the induction of the proliferation-stimulating activity of environmental oestrogens, suggesting anti-oestrogenic and anti-cancer effect; and naringenin attenuated many of the metabolic disturbances associated with ovariectomy in female mice. During the later preparative work, further well-known phytoestrogens were isolated from the $\mathrm{CH}_{2} \mathrm{Cl}_{2}$ layer of the methanolic extract of the fermented plant material: diosmetin, afrormosin, liquiritigenin (selective ER- $\beta$ antagonist), and formononetin (reported higher affinity towards ER$\beta)$. Hesperetin was also isolated, which was reported to be one of the most potent natural aromatase inhibitors.

The presence of these phytoestrogens gives a rationale to the traditional use of honeybush tea for menopausal symptoms. Although, in the literature different extracts from different Cyclopia species exerted varying phytoestrogenic activity, even between harvestings, questioning the real potential of medicinal use of honeybush. 


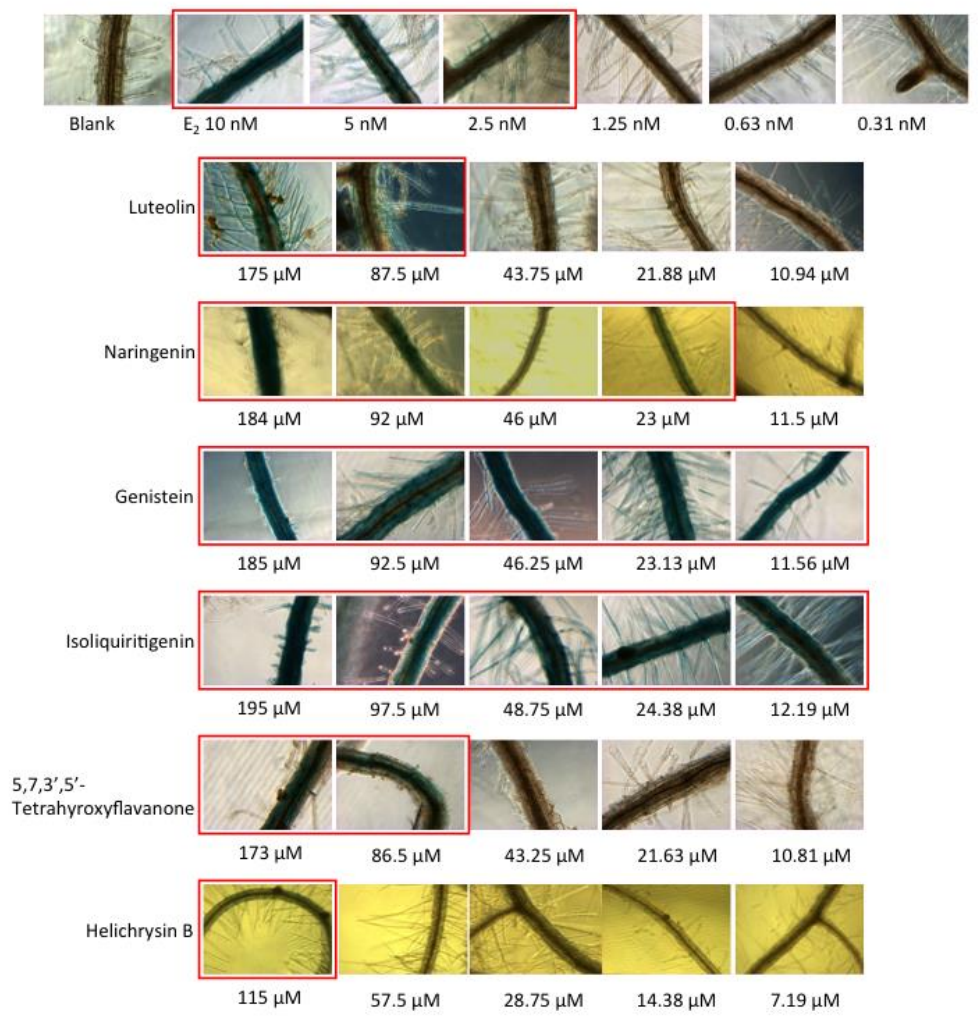

Figure 2. Oestrogenic MAC of the active isolated compounds in the histochemical assay. The concentrations where the blue colour was detectable, are surrounded with red boxes, indicating oestrogenic activity. The last/only concentration where the blue colour was still detectable was considered the minimum active concentration. $E_{2}$ : oestradiol

\section{HPLC quantification of compounds with oestrogen-like activity}

\section{and the rationale of fermentation}

The quantitative comparison of the six compounds with oestrogen-like activity between the fermented and non-fermented C. genistoides was performed by RP-HPLC. Peaks were identified by comparison of retention times and UV-Vis spectra (PDA detector) with those of the isolated compounds. 
While both the processed and unprocessed plant contained similar amounts of luteolin and isoliquiritigenin; the naringenin and 5,7,3', $5^{\prime}$-tetrahydroxyflavanone content in the fermented honeybush was more than 30 and 10 fold, respectively. On the other hand, the non-fermented Cyclopia had higher quantities of the naringenin-glycoside, which showed the weakest oestrogenlike activity amongst the six active compounds.

The quantitative comparison of the extract used for the bioactivity guided isolation (methanolic extract) and the traditionally used aqueous extract ("cup of tea extract") was also performed. The "cup of tea" extracts, prepared with boiling tap water, had much lower concentrations of the active compounds. Isoliquiritigenin was below the detection limit in the aqueous extracts, whereas $5,7,3^{\prime}, 5^{\prime}$-tetrahydroxyflavanone was undetectable in the water extract of the non-fermented sample. Genistein was not detected in any of the extracts.

Fermentation reduces the total phenolic content of Cyclopia spp., yet traditionally the fermented tea is consumed. The degradation of flavonoid-glycosides during the fermentation process could explain the difference in the measured amounts of the active compounds between the samples. On one hand, although our experiments reported potent and well-known phytoestrogens to be comprised by $C$. genistoides, the low concentrations of the tested compounds are questioning the potential phytoestrogenic activity of the traditionally used infusion of honeybush.

On the other hand, aqueous extracts of non-fermented or fermented $C$. genistoides and C. subternata were able to significantly displace $1 \mathrm{nM}\left[{ }^{3} \mathrm{H}\right]-\mathrm{E}_{2}$ from $\mathrm{hER} \beta$. Although, this effect was not observed in all tested harvestings, it did show the possibility of an aqueous extract to be oestrogenic. It also has to be noted, that the oestrogenic activity of Cyclopia extracts is the result of a fine balance between different polyphenols present in varying amounts with varying phytoestrogenic potential.

In another experiment the possible effect of the intestinal flora on aqueous extracts of fermented and non-fermented $C$. genistoides using commercially available mixture of probiotic bacteria was assessed. Naringenin and luteolin were quantified by HLPC before and after bacterial fermentation of the aqueous extracts. While both the processed and unprocessed plants contained similar amounts of luteolin, the naringenin content in the fermented honeybush was higher. However, after 50 hours of bacterial fermentation most likely due to the loss of sugar moiety, the naringenin and luteolin content was approximately similar in both the fermented and non-fermented honeybush.

The traditional fermentation process (high temperature oxidation) reduces the total polyphenolic content of Cyclopia spp., but according to our results, bacterial fermentation may 
increase the content of aglycones, which usually possess more pronounced bioactivities than their corresponding glycosides, and their bioavailability is remarkably higher than those of the respective glycosides.

\section{Antiproliferative activity}

In order to measure the antiproliferative effect of the isolated compounds, antiproliferative testing was conducted on T47D (ER positive) and A2780 (ER negative) human cancer cells.

While in the pER8:GUS assay P8-11, V2, V3, V6, V7 showed oestrogenic activity; in the antiproliferative tests, P8, P10, P11 and V3 demonstrated inhibition greater than $30 \%$ in either cell-lines. Except of helichrysin B and 5,7,3', $5^{\prime}$-tetrahydroxyflavanone, all compounds with oestrogen-like activity (naringenin, luteolin, isoliquiritigenin, genistein) exhibited substantial antiproliferative activity against the tested cell lines. All four of them had a greater inhibition towards the ER negative A2780, which may suggest an ER-independent inhibition of cell proliferation, or possibly the induction of cell proliferation in the ER positive T47D cell line; underlining their oestrogenic potential.

\section{Xanthine oxidase inhibitory activity}

Both dichloromethane layers derived from the methanolic extract of the fermented and nonfermented plant material exerted xanthine oxidase inhibitory activity thus were subjected to further chromatography. Fractions PP8 from the non-fermented and P10 from the fermented herbal substance were amongst the fractions with the strongest inhibition of xanthine oxidase. Further purification of these fractions led to the isolation of luteolin and diosmetin (CG1 and CG17) exerting remarkable XO inhibitory effect with $\mathrm{IC}_{50}$ values of $0.84 \mu \mathrm{M}$ (95\% confidence interval 0.80 to $0.91 \mu \mathrm{M})$ and $0.53 \mu \mathrm{M}(95 \%$ confidence interval 0.40 to $0.80 \mu \mathrm{M})$, respectively. The inhibitory activity of both compounds significantly exceeded that of allopurinol $\left(\mathrm{IC}_{50}=7.49 \pm\right.$ $0.29 \mu \mathrm{M})$, which was used as a positive control.

Alongside with the bioactivity-guided isolation, all other isolated compounds were tested. From the 15 already isolated constituents only two structurally close flavanones, hesperetin (CG12) and 5,7,3',5'-tetrahydroxyflavone (CG14) exhibited a weak inhibition (IC $50=55.20 \mu \mathrm{M}$ (95\% confidence interval 41.40 to $73.51 \mu \mathrm{M})$ and $120.55 \mu \mathrm{M}$ (95\% confidence interval 101.71 to $142.86 \mu \mathrm{M})$, respectively). The rest of the isolated compounds showed no xanthine oxidase inhibition ( $\left(C_{50}>150 \mu \mathrm{M}\right)$. 


\section{ACKNOWLEDGEMENTS}

I would like to express my greatest gratitude to the wonderful team of the Institute of Pharmacognosy; they supported me and created an atmosphere that stimulated me to do my best all the time. I am particularly thankful to my supervisor, Dr. Dezsö Csupor, who was always there for me, even in the busiest times. His encouragement and professional advice made priceless contribution to my work.

I am grateful to Prof. Dr. Judit Hohmann, for the management of my work and her continuous support. I also wish to thank Dr. Katalin Veres and Dr. Dóra Rédei, who introduced me to the world of research and inspired me to start and continue my PhD.

My special thanks for Dr. Andrea Vasas, who gave me scientific guidance and much more.

Huge thank for Dr. Ana Martins, who helped me in many ways and places during my PhD years.

I am grateful to Prof. Kálmán Szendrei and Dr. Attila Hunyadi for fuelling me with ideas that inspired my work. I am thankful to Dr. Jacobus $\boldsymbol{N}$. Eloff for the collection of the plant material.

I owe special thanks Dr. Ildikó Lajter who was my right hand all way long (and I am her left).

I am also grateful to Prof. Fang-Rong Chang, who made it possible to perform a big part of my experiments in his laboratory and Dr. Wan-Chun Lai who taught me new techniques and gave me precious support. Financial support from the European Union and the State of Hungary, cofinanced by the European Social Fund in the framework of TÁMOP-4.2.4.A/ 2-11/1-2012-0001 'National Excellence Program' is gratefully acknowledged.

I would like to thank Eszter Kozma, who gave me the inspiration to begin my PhD work.

I am very thankful for Dr. Nikolett Jedlinszki, Dr. Zoltán Kele, Norbert Kúsz, and Balázs Dankó for the NMR and MS measurements. I am grateful for Dr. Attila Ványolós for the trust he put in me. I am also thankful to Dr. Botond Lajos Borcsa and Dr. Szilárd Vajda for encouragement in difficult times.

I would also like to thank to Dr. István Zupkó and Dr. Norbert Lovász for the antitumor activity experiments and organ-bath studies. I am very grateful for the valuable help, positive energy and excellent technical assistance of Erzsébet Berta Hadárné, Anna Herkéné Nagy and Ibolya Hevérné Herke. I would like to thank Attila Horváth and Klára Boros, my friends for the excellent and persevering support in the HPLC measurements and beyond.

Last but not least I would like to thank God to make everything possible, to my partner, Ed for his love, support and inspiration, to my family and friends, my cornerstones in life. They helped me in countless different ways during these years. 
THE THESIS IS BASED ON THE FOLLOWING PUBLICATIONS:

1. Roza O, Lai W-C, Zupkó I, Hohmann J, Eloff JN, Chang F-R, Csupor D.

Bioactivity guided isolation of phytoestrogenic compounds from Cyclopia genistoides by $p$ ER8:GUS reporter system

South African Journal of Botany 2016; In Press

If: $1.244(2015)$

2. Roza O, Martins A, Hohmann J, Lai W-C, Eloff JN, Chang F-R, Csupor D.

Flavonoids from Cyclopia genistoides and their xanthine oxidase inhibitor activity

Planta Medica 2016; 82:1274-1278

If: $2.152(2015)$

3. Roza O, Lovász N, Zupkó I, Hohmann J, Csupor D.

Sympathomimetic Activity of a Hoodia gordonii Product: A Possible Mechanism of Cardiovascular Side Effects

BioMed Research International 2013; Article ID: 171059

If: 2.706

\section{Presentations held in the theme Of THe thesis:}

1. Roza O, Martins A, Hohmann J, Lai W-C, Chang F-R, Eloff JN, Csupor D.

Polyphenols from Cyclopia genistoides and their xanthine oxidase inhibitory activity

$63^{\text {rd }}$ International Congress and Annual Meeting of the Society for Medicinal Plant and Natural Product Research - GA2015; Budapest, Hungary, 23-27 August 2015

2. Csupor D., Roza O., Jedlinszki N., Hohmann J.

Szintetikus hatóanyagokkal hamisított növényi fogyasztószerek vizsgálata

Congressus Pharmaceuticus Hungaricus; Budapest, Hungary, 10-12 April 2014

3. Roza O., Martins A, Csupor D, Hohmann J.

A Cyclopia genistoides xantin-oxidáz gátló hatásának vizsgálata

Fiatal Gyógynövénykutatók Fóruma; Budakalász, Hungary, 14 February 2014

4. Roza O, Lai W-C, Chang F-R., Boros K, Csupor D.

Investigation of the phytoestrogenic activity of Cyclopia genistoides by pER8:GUS reporter system

$62^{\text {nd }}$ International Congress and Annual Meeting of the Society for Medicinal Plant and Natural Product Research - GA2014; Guimaraes, Portugal, 31 August-4 September 2014

5. Roza O, Lovász N, Zupkó I, Hohmann J, Csupor D.

Hoodia gordonii: facts beyond beliefs

Trends in natural products research: a young scientists meeting of PSE and ÖPhG; Obergurgl, Austria, 21-25 July 2013 